Review

\title{
Randomized controlled trials and real life studies. Approaches and methodologies: a clinical point of view.
}

\author{
S. Saturni ${ }^{a}$, F. Bellini ${ }^{a}$, F. Braido ${ }^{b}$, P. Paggiaro $^{c}$, A. Sanduzzi ${ }^{d}$, N. Scichilone ${ }^{\text {e }}$, P.A. Santus ${ }^{f}$, \\ L. Morandi ${ }^{\text {a }}$, A. Papi ${ }^{\mathrm{a}, *}$ \\ a Respiratory Medicine, Department of Medical Sciences, University of Ferrara, Ferrara, Italy \\ ${ }^{\mathrm{b}}$ Allergy and Respiratory Diseases Clinic, DIMI, University of Genoa, IRCS AOU San Martino-IST, Genoa, Italy

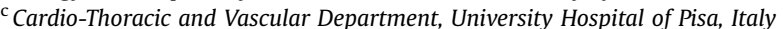 \\ ${ }^{\mathrm{d}}$ Section of Respiratory Diseases, Department of Surgery and Clinical Medicine, University of Naples, Italy \\ e Department of Internal Medicine, Section of Pulmonology (DIBIMIS), University of Palermo, Italy \\ ${ }^{\mathrm{f}}$ Dipartimento di Scienze della Salute, Pneumologia Riabilitativa, Fondazione Salvatore Maugeri, Istituto Scientifico di Milano IRCCS, University of Milan, \\ Milan, Italy
}

\section{A R T I C L E I N F O}

Article history:

Received 3 November 2013

Received in revised form

11 January 2014

Accepted 13 January 2014

\section{Keywords:}

Randomized controlled trials

Real life studies

Asthma

COPD

\begin{abstract}
A B S T R A C T
Randomized Controlled Trials (RCTs) are the "gold standard" for evaluating treatment outcomes providing information on treatments "efficacy". They are designed to test a therapeutic hypothesis under optimal setting in the absence of confounding factors. For this reason they have high internal validity. The strict and controlled conditions in which they are conducted, leads to low generalizability because they are performed in conditions very different from real life usual care. Conversely, real life studies inform on the "effectiveness" of a treatment, that is, the measure of the extent to which an intervention does what is intended to do in routine circumstances. At variance to RCTs, real life trials have high generalizability, but low internal validity. Recently the number of real life studies has been rapidly growing in different areas of respiratory medicine, particularly in asthma and COPD. The role of such studies is becoming a hot topic in respiratory medicine, attracting research interest and debate.

In the first part of this review we discuss some of the advantages and disadvantages of different types of RCTs and analyze the strengths and weaknesses of real life trials, considering the recent examples of some studies conducted in COPD. We then discuss methodological approaches and options to overcome some of the limitations of real life studies.

Comparing the conclusions of effectiveness and efficacy trials can provide important pieces of information. Indeed, these approaches can result complementary, and they can guide the interpretation of each other results.
\end{abstract}

(c) 2014 Elsevier Ltd. All rights reserved.

\section{Introduction}

Research evolves by answering new questions, including questions on how research itself should be conducted. Randomized Controlled Trials (RCTs) are well recognized as the "gold standard" for evaluating treatment outcomes $[1,2]$. They are designed to test a

Abbreviations: RCTs, randomized controlled trials; COPD, chronic obstructive pulmonary disease; CAP, community acquired pneumonia; CF, cystic fibrosis; ITT, intention-to-treat; ICSs, inhaled corticosteroids; BA-pMDIs, breath-actuated pressurized metered dose inhalers; DPIs, dry powder inhalers; pMDIs, pressurized metered dose inhalers; LABA, long acting beta2 agonist; LTRA, leukotriene receptor antagonists; LRTIs, lower respiratory tract infections.

* Corresponding author. Section of Respiratory Medicine, University of Ferrara, Via Savonarola 9, 44121 Ferrara, Italy. Tel.: +39 0532236908.

E-mail addresses: ppa@unife.it, alberto.papi@unife.it (A. Papi). therapeutic hypothesis under optimal conditions in the absence of confounding factors: highly selected patients, optimal management conditions, and ideal settings; thus they provide information on "efficacy" under conditions very different from real life [3,4]. They accomplish this through an experimental design $[2,5,6]$ that, as their name implies, always includes randomization to guarantee that treatment groups are as similar as possible in all attributes that could potentially influence outcomes $[2,5]$. Thus, RCTs have high internal validity under the ideal conditions in which they are conducted $[1,2]$. Concerns about the conclusions of RCTs relate mainly to their generalizability to broader patient populations and to less ideal conditions, like routine clinical practice, where even health care costs and availability can be problematic [2]. Indeed, it is argued that, because of statistical need of limiting confounding factors, the highly selected population of RCTs only partially 
represents the real-life population, casting doubts on the external validity of these clinical trials. Assessment of outcomes under these sub-optimal conditions in observational or pragmatic studies informs on the "effectiveness" of a treatment in real life [3,4], that is, the measure of the extent to which an intervention does what is intended to do in routine circumstances.

Observational studies have the power and structure to identify areas in which investigation is needed and to test new hypotheses [7]. Pragmatic trials are designed to evaluate treatment outcomes, but unlike RCTs they adopt usual care settings and procedures in non-selected patients [7], thus mimicking everyday clinical practice, which provides high external validity. Real life studies have limitations, primarily stemming from the lack of randomization and the need to apply the indications only within the local geographic context.

In the first part of this review, we will mainly refer to real life studies conducted in asthma, where they have a long history, as documented by the large number published in the last 10 years. Recently the number of real life studies in pharmacological has been rapidly growing in other areas of respiratory medicine, particularly chronic obstructive pulmonary disease (COPD) (Fig. 1). During the same period the overall number of RCTs in asthma and COPD was several times higher and tended to be constant over time: there were on average more than 400 RCTs every year on asthma $( \pm 5 \%)$ and more than 200 RCTs/year on COPD $( \pm 8 \%)$.

The progressive increase of real life studies published in the last years and their recognized scientific value $[8,9]$ underline that their role is becoming constructive in respiratory medicine, attracting research interest and debate $[10,11]$. The second part of the review will consider some of the advantages and disadvantages, strengths and weaknesses of different types of trials and comment on the complementarity between RCTs and real life studies.

\section{Randomised Controlled Trials}

\subsection{RCTs: definition and features} [12].

RCTs are research studies that aim to evaluate treatment efficacy

Evidence-based clinical trials start from the formulation of a research hypothesis [13], which may be an evaluation of "superiority" or "equivalence" [13]. The appropriate primary outcome and corresponding measuring tool are chosen [13] and the number of

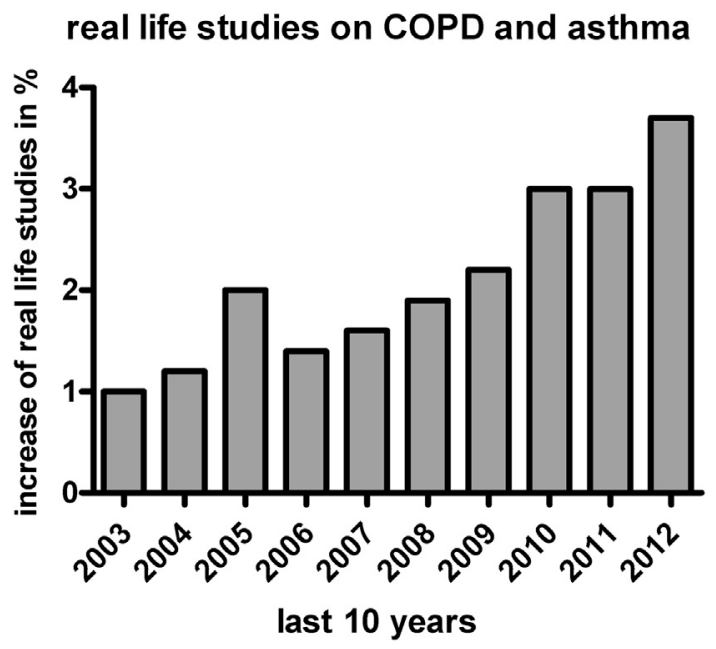

Fig. 1. Real life studies in asthma and/or COPD in the last decade. PubMed search: Percent variations in the last decade of published studies on asthma and/or COPD containing the term "real-life" in the title or abstract. patients is estimated based on statistical parameters, historical data on the working hypotheses, clinically relevant differences and the inherent variability of the primary outcomes.

Random assignment to treatment groups and double blind monitoring minimize bias [13].

The effect of the tested treatment is assessed by comparing it to a control condition, standard treatment or placebo [13]. Different treatment strategies or dosages can also be compared. These criteria maximize internal validity but at the same time, limit generalizability and reduce external validity [14].

\subsection{RCTs: advantages}

Because of their internal strength, RCTs are universally accepted as the "gold standard" for assessing the effects of therapeutic interventions and of medical devices/equipment under specific controlled conditions [7,15-19].

Historically, the first RCTs available in the respiratory literature addressed community acquired pneumonia (CAP), but they did not follow all of the strict RCT rules. A critical assessment of the early studies revealed design flaws: the diagnosis of pneumonia was not defined in $42.8 \%$ of the RCTs, only $33 \%$ of the studies were restricted to CAP, and outcomes were not defined in $28.5 \%$ of the studies [20]. Moreover, only $38 \%$ of the RCTs were double-blinded, and intention to treat analysis was not applied [20]. During the ensuing years, significant improvements were made in all methodological aspects of RCTs in respiratory medicine. One of the most recent published RCT on respiratory infections [21] evaluated macrolide maintenance treatment with azithromycin in adults with bronchiectasis not due to cystic fibrosis (CF) [21]. This study meets the criteria for a well-conducted RCT. It has an appropriate design, randomization, double blinding, placebo control and analysis by intention-to-treat (ITT) [21].

The validity of RCTs is built around precise requisites (Table 1), starting from a careful and rigorous experimental plan. Scientists must establish the aim, the primary and secondary outcomes, size

Table 1

Advantages and disadvantages of RCTs and real life studies.

\begin{tabular}{|c|c|c|}
\hline & RCTs & Real life studies \\
\hline Advantages & $\begin{array}{l}\text { - Rigorous experimental } \\
\text { design } \\
\text { - Randomization } \\
\text { - Blinding } \\
\text { - Control } \\
\text { - Rigorous analysis methods }\end{array}$ & $\begin{array}{l}\text { - Non-selected population } \\
\text { - Refer to the usual } \\
\text { inhaler techniques } \\
\text { - Realistic therapy } \\
\text { adherence } \\
\text { - Logistical and ethical } \\
\text { feasibility } \\
\text { - Able to evaluate } \\
\text { complex therapies } \\
\text { - Useful to detect rare } \\
\text { or late side effect } \\
\text { - Routine practice setting } \\
\text { - Long duration }\end{array}$ \\
\hline Disadvantages & $\begin{array}{l}\text { - Selected patients } \\
\text { - Setting and monitoring bias } \\
\text { - Economical limitations } \\
\text { - Logistical and ethical } \\
\text { restrictions } \\
\text { - Unsuitable for complex } \\
\text { treatments studies } \\
\text { - Inappropriate for thorough } \\
\text { evaluation of side effects } \\
\text { - Short duration }\end{array}$ & $\begin{array}{l}\text { - Lack of patient selection } \\
\text { brings confounding factors } \\
\text { - Lack of randomization } \\
\text { - Absence of blinding } \\
\text { - Residual monitoring bias } \\
\text { - Confounding by indication } \\
\text { - Economical limitations } \\
\text { - Logistical problems } \\
\text { - Immortality bias }\end{array}$ \\
\hline
\end{tabular}

Table 1 describes the main advantages and disadvantages of both RCTs and real life studies. Advantages and disadvantages of RCTs are associated to their strict design and population selection, which make their conclusion robust but distant from real life conditions. On the other side, real life studies reflect more closely related to usual care, but they provide results obtained in sub-optimal treatment conditions. 
and characteristics of the study population, the randomization method, the control, the analysis method and all other phases or components of the trial [2].

The randomization process by which patients are allocated to treatment groups is a key element of RCT design. It guarantees that the groups are equal and comparable in all known and unknown characteristics that could potentially influence outcomes [2,12]. With this type of distribution, the groups differ only in their exposure to the treatment investigated [22]. This procedure avoids selection bias since every person has the same probability of receiving the test treatment(s) or the control [12].

In addition to randomization, also blinding reduces the possibility of bias. In a well-designed RCT, people directly involved in the study do not know how patients were allocated to treatments [23]. This avoids confounding factors linked to subjective perception of therapeutic effects because patients and health-care providers managing the therapy administration are unaware of the treatment assigned. Blinding of outcome assessors increases the reliability of the results because it assures the same interest and attention to each patient and to every result, minimizing also detection bias, i.e. systematic errors linked to evaluation of the results [23,24]. A distinctive feature of RCTs is the presence of a control for comparison. With proper controls, an RCT can provide a relative evaluation of efficacy, increasing the consistency of the conclusions. Controls for comparison allow a more objective evaluation of the effect and increase the robustness of the study design.

RCTs require an analytical approach to data analysis, to avoid methodical systematic bias. This is typically obtained by using ITT analysis [23,25], one of the strongest methods to prevent analytical bias $[13,23]$.

ITT analysis considers that all patients belong to the groups to which they were initially randomly assigned, even if they subsequently withdraw or move/switch to another treatment group. Patients who do not receive the assigned treatment should not be excluded from the planned analysis since they usually do not have the same prognostic features as the others [23].

\subsection{RCTs: limitations}

Even the best RCT has limitations, because its well-defined structure implies some artifacts. Indeed, although RCTs are precious tools to assess treatment efficacy, their applicability is restricted to ideal conditions and this limits their ability to portray what happens in the real world [7,14,26-29] (Table 1).

One of the more relevant limitations of RCTs is a direct consequence of rigorous patient selection based on selective inclusion and exclusion criteria [7]. The reason behind such selective enrollment is to minimize the presence of confounding factors [7]. Thus, a "trial" population is selected and differs from the general population [30]. A Norwegian study recently evaluated the magnitude of this difference by assessing the actual population referred to an asthma clinic using the inclusion and exclusion criteria commonly adopted in RCTs in asthma (e.g. non-smokers with a defined range of airflow obstruction and no comorbidities, 1-2 exacerbation in the previous 12 months but none in the last month, symptomatic or not when treated with specified doses/ types of medication). They found that less than 3\% of the real population would be eligible for randomization. This is clearly not representative of the asthma population attending an asthma clinic in real life [31]. A similar study reported that less than $20 \%$ of patients with COPD meet the usual enrollment criteria for RCTs in COPD [31]. More recently, it has been confirmed that, by applying the commonly adopted inclusion/exclusion criteria to a large population of individuals with an established diagnosis of COPD, less than one out of five patients would be eligible for the RCTs [32].
Consequently, RCTs do not consider a number of factors that potentially influence outcomes in real life [14,33-37]. In particular, tobacco smoking, concomitant diseases, adherence to treatment should be considered because it affects responsiveness to corticosteroids $[29,38,39]$, the first choice treatment for asthma.

Interestingly, the majority of asthma trials do not accept current/former smokers, while the majority of COPD trials exclude asthmatics, so there are no data on the large subgroup of patients ( $\sim 30 \%$ ) who have poor lung function and unfavorable clinical outcomes (e.g. frequent hospitalizations) [29,40-43].

Elderly asthmatic patients are another group traditionally excluded from RCTs, even though this clinically relevant population experiences high rates of hospitalization and asthma related death $[29,44,45]$. Excluding such patients and, for example those with comorbidities, results in a lack of treatment solutions in exactly the groups where they could have high clinical impact [29,46].

In clinical practice comorbidities are frequently encountered in patients with obstructive lung diseases. They are reported in more $30 \%$ of asthmatic patients and in the majority (>60\%) of COPD patients [31]. Concomitant diseases can affect the clinical manifestation of respiratory disorders (e.g. increasing risk of COPD exacerbations) [47,48] and their responsiveness to treatments (e.g. depression or other psychological problems reduce adherence to therapy, and obesity is associated to a lower response to inhaled corticosteroids) $[49,50]$. In addition, the presence of comorbidities can influence the pharmacological approach to obstructive lung diseases, e.g. the use of $\beta 2$-agonists and of $\beta$ blockers in patients with obstructive lung diseases and concomitant heart problems $[48,51,52]$. In general, the interplay between concomitant diseases/ treatments cannot be properly assessed in RCTs.

On the other side, strict selection might focus only on patients who will respond better to the tested treatment leading to overestimation of treatment effects [53]. Patients included in RCTs are usually adept at inhalation techniques: they are instructed on the use of inhalers and frequently monitored. Adherence to treatment is usually high in RCTs as this is a prerequisite for randomization, assessed during run-in: a sort of pre-selection of the population that can maximize treatment effects [14]. Clearly, this does not reflect everyday clinical practice, largely characterized by poor inhaler technique and low treatment observance [7,14,54]. In addition, subjects participating in RCTs are more likely to follow instructions [22,55]. Subjects enrolled in studies tend to pay closer attention to their health. This may minimizing any further advantages from the trial intervention and result in underestimation of preventive effects $[22,55,56]$.

Interestingly, differences in patient selection criteria between RCTs may produce conflicting results for a given outcome [10,57]. For instance, there are contradictory data on the protective efficacy of bacillus Calmette-Guérin vaccine in the prevention of tuberculosis, probably linked to various diagnostic criteria used in different settings $[10,58,59]$.

In addition to selection bias, RCTs have also a monitoring bias linked to the higher frequency of assessments and visits, compared to clinical practice [13]. The awareness of being monitored can influence outcomes by improving performance and reducing dissimilarities between different therapies. In addition, placebo effect may reduce the difference between active and control treatment, not only on subjective but also on objective measurements [14,6062].

Another possible bias of RCTs derives from the clinical setting of the trial. Often the patient population is followed in specialized centers, where the available specialists and technologies differ from those in most general practice settings [11]. Thus, patient management in RCTs is not representative of usual care [11]. In addition, at variance with daily practice [63], RCTs usually comply with 
international guidelines classifications to assess disease severity and treatment appropriateness.

RCTs have economical, logistical and ethical restrictions that can make them inappropriate for analyzing issues related to public health systems or unsuitable for specific conditions. For example, their design cannot be applied when evaluating rare conditions. Similarly, they cannot be utilized when the study concerns the cost, convenience, or safety of a therapy, but not its efficacy [2]. Moreover, RCTs do not take into account that each treatment becomes part of the complex health care system. This can potentially influence the use of the medication in daily practice in different ways, including accessibility and price/reimbursement, which often differ by country [2].

Because of feasibility limitations, RCTs usually assess a single distinct intervention in a specific setting. They have limited possibility to investigate the complex treatments common in real life, especially in the elderly and polymorbid populations [2,5]. For these reasons, the strict design of RCTs does not allow full detection of the side effects or complications associated with an intervention, particularly if these result from pharmacological interactions or concomitant comorbidities, or if they have a delayed onset $[1,2,5,6]$. Timing is another constraint with RCTs, which frequently have duration of weeks or few months [7,14,64-66]. Such a timeframe minimizes problems with management, costs, and patient withdraws [7,64-66], but is significantly shorter than the usual treatment period for chronic respiratory diseases [13]. This limits their ability to provide reliable information on long-term treatment [2,14].

In summary, there is an urgent need for clinical information beyond that obtainable from classical RCTs. Recent concerns have been raised regarding the safety of the patients enrolled in RCT and exposed to a standard (not tailored) and unknown (double blinded) care [67]. Thus, it is not surprising that, in the past ten years, there has been an impressive increase in the number of the real life studies in asthma and COPD [68-75].

\section{Real life studies}

\subsection{Real life studies: definition and features}

Real life studies have been described in a variety of ways. The European Working Group on Relative Effectiveness has defined real life trials as a way to analyze medical data collected under real life conditions [27]. In essence, they are conducted in everyday settings, and for this reason, they provide insights into the real life effectiveness of a medical condition/intervention.

They can be observational or descriptive, i.e. non-interventional, or they can evaluate therapeutic interventions in usual care settings [27]. Numerous strategies have been described for collecting data to inform real world clinical decisions. Examples include databases, patient and population surveys, chart reviews, registries, observational studies and pragmatic clinical trials (Table 2) [27]. However, observational and pragmatic trials are the most widely used.

Observational studies are designed to monitor and describe real life management/treatment of clinical conditions, without interference from the strict rules that limit the generalizability of RCTs. They can be both prospective and retrospective and consist of cohort, case-control and cross-sectional studies [14]. By nature, they can assess large populations over long follow-up periods.

Pragmatic clinical trials are the type of real life studies closest to RCTs: they compare treatments/clinical interventions. At variance with RCTs, pragmatic trials are conducted in a routine care setting with heterogeneous patient populations and prolonged durations, which increase the likelihood of obtaining conclusions relevant to clinical practice $[14,30,76-78]$.

The reliability and feasibility of analyzing data from real life sources are debated because of the variable quality of data from primary (medical records) or secondary (healthcare databases) sources $[10,79]$. For example, in different hospital databases the same pathological condition may be registered under different names (e.g. pulmonary fibrosis or interstitial lung disease) and this could influence subsequent data analysis. Whereas a single source usually registers such data under the same category; however, this means that any mistakes in diagnosis/management are repeated for all cases. Currently, there is no consensus on the best way to collect such data, but comparing the information obtained from various types of registries seems reasonable. When lung function data are available the risk of under/misdiagnosing obstructive lung diseases is reduced [80].

\subsection{Real life studies: advantages}

Real life studies reflect how treatments/interventions are administered in everyday clinical practice (Table 1 ). At variance to RCT, real life studies in asthma involve a heterogeneous nonselected population that includes smokers, all level of disease severity, atypical patients, patients with comorbidities, and those with low adherence and poor inhaler handling or inhalation technique $[81,82]$. This insures that every subject who potentially will receive the test treatment is represented in the study [81] Real life studies do not use inclusion and exclusion criteria: being nonselective they can include all the variables that can influence outcomes under real life conditions. This qualifying characteristic may lead to discrepancies with the results obtained by RCTs for a given outcome. Such is the case for asthma control, which is attained in a large proportion patients in RCTs, but not in real life conditions [7,83]. This may be due to differences in education on inhaler handling and in the choice of the most suitable inhaler for each patient $[14,84]$. RCTs and guidelines do not ascribe differences in clinical outcomes to inhalers [14,17,19,85-87], possibly because

Table 2

Types of real life studies.

\begin{tabular}{|c|c|c|}
\hline Type & Characteristics & Application \\
\hline Databases & $\begin{array}{l}\text { - Cross-sectional or longitudinal analysis of } \\
\text { previously collected data. }\end{array}$ & - Retrospective data analysis on various topics. \\
\hline Population surveys & - Surveys, patient health status and opinion assessment. & - Epidemiological studies. \\
\hline Patient chart reviews & $\begin{array}{l}\text { - In depth evaluation of previously collected data, particularly } \\
\text { focusing on diagnosis and treatment. }\end{array}$ & - Assessment of disease management for planning guidelines. \\
\hline Registries & $\begin{array}{l}\text { - A medical institute record of all patients treated for a } \\
\text { specific disease. }\end{array}$ & $\begin{array}{l}\text { - Analysis of a medical centre experience/management/changes } \\
\text { in the treatment of a disease. }\end{array}$ \\
\hline Observational data & $\begin{array}{l}\text { - Prospective or retrospective data collection, usually on } \\
\text { population cohorts, over a long follow-up period. }\end{array}$ & $\begin{array}{l}\text { Examination of medical intervention effectiveness, including } \\
\text { safety and tolerability. }\end{array}$ \\
\hline Pragmatic trials & $\begin{array}{l}\text { - Assesses treatment outcomes in the context of real-life } \\
\text { clinical practice. }\end{array}$ & - Compare interventions under routine clinical circumstances. \\
\hline
\end{tabular}

This table describes the main types of real life studies, their features, including the source of data, and their applications in effectiveness studies. 
patients in RCTs are adequately instructed in the proper use of their devices [14,88]. Conversely, differences emerge from real life studies, particularly in asthma, one of the first clinical conditions in which inhaler technique was investigated. An observational study revealed that using the same type of inhaler device for maintenance and rescue medication improved clinical results [89]. A cohort study demonstrated that monotherapy with inhaled corticosteroids (ICS) is more successful when patients use breathactuated pressurized metered dose inhalers (BA-pMDIs) or dry powder inhalers (DPIs) rather than pressurized metered dose inhalers (pMDIs) [90]. Interestingly, the opposite was found for combination therapy ICS + long acting beta2 agonist (LABA), where a cohort study reported that a pMDI formulation of fluticasonesalmeterol provides greater benefits than a DPIs formulation [91]; moreover, a cross-sectional trial demonstrated that an extrafine formulation of beclomethasone-formoterol combination pMDI leads to better asthma control than ICS/LABA formulations DPIs [92]. These apparently conflicting results require careful interpretation but they underscore the importance of device selection and show how it can potentially influence clinical outcomes in real life.

Adherence to inhaled treatment is a major issue in routine practice and may represent another factor responsible for the difference between the results from RCTs and real life studies. In a recent survey, $18 \%$ of patients with chronic respiratory disorders reported discontinuation of the prescribed inhaled treatment because the difficulties in using the inhalers [93]. Several real life studies have assessed adherence to asthma medication with different formulations and treatment regimens. One study compared adherence rates to once-daily versus twice-daily mometasone furoate and found that the once-daily regimen is associated with better compliance [94]. Moreover, this study included non-adherent patients in the final analysis, thus providing valuable information for real life practice [94]. Evidence of how real life variables can subvert the ideal conclusions from RCTs was provided in a study on the efficacy of leukotriene receptor antagonists (LTRAs), a second line treatment for asthma in adults in RCT settings [95]. This study was a multicenter pragmatic trial that compared the real world effectiveness of 1) LTRA with low dose inhaled glucocorticoid as first-line asthma-controller therapy, and of 2) LTRA with LABA as add-on therapy in patients not controlled by low dose ICS [95]. The treatments were proven to be equivalent for asthma control, with a greater compliance to oral treatment compared to inhaled treatment, which contribute to make a second line oral treatment (LTRA) appear as effective as first choice inhaled treatment [95]. This was confirmed in children, where adherence to monotherapy with LTRA was better than to that of ICS [96]. Thus, in real life, higher adherence to an oral medication compared to an inhaled medication (ICS) may overturn the conclusions on efficacy obtained in RCTs $[14,95,96]$.

Real life studies are immune to the logistical and ethical constraints that limit the feasibility of RCTs. The absence of these limitations endows observational studies with the power to assess outcomes such as hospitalization and mortality [16], and enables pragmatic trials to estimate cost-effectiveness under real life conditions $[7,28]$. Comparing the results from observational trials versus RCTs on these issues reveals that estimates of cost-effectiveness based on RCTs lack external validity [97], while real life studies are more reliable as they reflect everyday clinical practice [28].

The characteristics of real life studies make them useful tools for evaluating complex therapies, and policies for prescribing and management $[76,98]$. An observational study in patients experiencing an acute asthma attack reported on prescribing patterns before accessing the emergency department [99]. This analysis determined that a lack or delay in medical intervention substantially affected the level of optimal asthma management. Such information cannot be obtained from RCTs, where the disease management plan is pre-defined, including emergencies events, without variability in the treatment or timing of interventions $[7,100]$. In addition, at variance with RCTs, which usually compare treatments and placebo, real life studies are able to integrate alternative health care options, providing information on the management of complex interventions, which are very common in the routine health care setting and influence the clinical decision process [76]. A typical example is represented by the potential cardiovascular effects of bronchodilators in patients with cardiovascular comorbidities that are excluded from the majority of RCTs.

The nature and characteristics of real life studies make them the appropriate setting to assess safety. Their large scale and long duration in non-selected populations favor the identification of rare complications or interactions with other treatments.

An additional advantage of real life studies is their natural practice setting, e.g. physicians' offices or clinics, which ensures that they have external validity [76]. Involvement of patients from different settings increases the variability of the results, but also reproduces the complexity of the health care system more reliably than the controlled conditions in RCTs [76].

Finally, real life studies have the benefit of longer durations than RCTs. This timing permits a more appropriate assessment of the long-term effects of medical interventions, and the identification of late side effects, by following the natural course of a disease [76].

Thus, real life studies have many positive features and play a key role in the investigation of clinical conditions and interventional opportunities. These intrinsic values explain the increasing importance of such studies in clinical research.

\subsection{Real life studies: limitations}

The limitations of real life studies are often intrinsically associated with their characteristic design (Table 1). The proximity to the real world, with all its complexity, including different disease manifestations, comorbidities, variable treatment adherence, suboptimal inhaler technique and multiple therapies, often dilutes the magnitude of a treatment effect [7].

The lack of patient selection, one of the most distinctive characteristics of real life studies, makes it impossible to avoid unmeasured confounding factors [11,29], while the absence of blinding and randomization does not always allow factors potentially influencing the outcomes to be properly balanced $[14,53,101]$. This is particularly true in studies with subjective outcomes, which can be influenced even by the patient's awareness of the treatment they are assigned to $[24,30]$. However, this "knowledge effect" can be interpreted as a component of the treatment response that is normally present in clinical practice. Thus, it can be compared to a "placebo effect" and the difference between the overall treatment effect observed (including the knowledge effect) and the "placebo (knowledge) effect" can provide a reliable estimate of effectiveness [3].

Another challenge for real life studies is monitoring. Although real life studies are planned to avoid the strict monitoring of RCTs, some conditions, such as pragmatic trials, require frequent measurements and medical supervision [7,14,102-105]. This tight assessment can result in patient responses that differ from those attainable in routine clinical practice. Indeed, each extra visit potentially increases the patient's response to therapy [106,107].

Under real-life conditions, in the absence of randomization, severity of the underlying disease influences treatment decisions [108]. This results in "confounding by indication", meaning that the perception of a different prognosis leads the physician to preferentially prescribe one of the available treatments. As a result, prognostic factors are not equally distributed among the patients treated with different therapies and the comparison is affected by disease 
severity [108], when patients treated with one medication are systematically different from the other groups in terms of illness stage [53]. In addition, it is common clinical practice to follow severe patients more closely [108,109]. This difference in monitoring influences the results of real life studies. Sometimes the disease per se requires a specific medical intervention, so the disease, not its severity, represents the "confounding by indication" factor. In this case, the severity/prognosis is considered a subtype of "confounding by indication" [110]. An interesting example of this type of bias comes from pediatric studies suggesting that the development of asthma in children $<5$ years old is associated with the use of antibiotics [111,112]. This association was identified when antibiotics are prescribed for lower respiratory tract infections (LRTI) [113,114]. In this case, the increased risk of asthma could be associated with LTRI, rather than antibiotics. Indeed, children with severe LTRI requiring antibiotics may be predisposed to developing asthma [115].

Economical and logistical demands pose an additional challenge for real life studies. Indeed, long-term studies involving large populations require considerable financial resources [76] and are logistically complex to manage. Long follow-up may represent a barrier to patient retention over the entire study period. Moreover, large populations are required to detect small treatment differences or infrequent clinically events (e.g. rare side effects) [30].

Finally, in observational studies, the choice to treat is not strictly regulated and can be made at any time during the disease history/ evolution. The results of observational studies showing that prescription of ICS for COPD reduces the risk of subsequent hospitalization and mortality were said to be affected by an "immortality bias" [116]. In these studies, patients were considered to be "exposed" to ICS, if it was prescribed within 90 days after hospital discharge [116]. By definition, exposed patients could not incur rehospitalization or mortality (outcomes of the assessment) before glucocorticoids were prescribed [117]. Thus, they were technically outcome-free for up to 90 days, the so-called "immortal" follow-up time. This potentially leads to overestimation of the effect of ICS on these outcomes [16,117].

Therefore, it emerges that, although they reproduce real life conditions, real life studies sometimes differ from authentic routine clinical practice. Every artifact, large or small, potentially averts from genuine results.

\subsection{Real life studies: overcoming some of the limitations}

Investigators have acknowledged the limitations of real life studies and the search for solutions has begun (Table 3). A good starting point for increasing reliability is to establish a study plan with a critical design, a priori [7]. Given the importance of balancing the variables among the groups assessed, even observational cohorts can be designed with eligibility criteria. Enrolling patients with specific characteristics can improve the consistency of the results [118].
The study report should be prepared following strict guidelines that aim for the correct, accurate and reliable presentation of results $[7,77,119]$. For this purpose, the Consolidating Standards of Reporting Trials (CONSORT) statement, initially created for the standardization of RCTs [120], has been extended to cover also pragmatic cluster trials, where randomization applies to groups rather than individuals [121,122]. The CONSORT guide is a checklist of items to incorporate in the study report in order to provide a clear explanation of study procedures and analyses. This guide also suggests that a flow diagram be used to specify the role and position of every subject involved in management of study [7,77]. Similarly, the Strengthening the Reporting of Observational Studies in Epidemiology (STROBE) statement is a systematic checklist of items that define the characteristics of an observational study [119]. These tools for transparent reporting facilitate clear reporting of data and help editors, reviewers and readers to critically evaluate the aim and results of clinical studies [119].

Sources of bias linked to the timing of follow-up, such as the "immortal period", can be addressed by using a time-dependent analysis that includes all treatments prescribed after enrollment, and arranging follow-up using a time-varying approach [16]. This more complete analysis permits a better understanding of temporal dynamics [16].

The absence of randomization clearly limits the reliability of conclusions from real life studies; however, differences between groups can be minimized. One of the most effective methods to control for equality between groups is propensity score matching [123]. This analysis quantifies the probability that a patient will receive treatment, assigning a numerical value based on disease severity, concomitant diseases, clinical history, prognostic parameters and other variables [124]. Subjects in different treatment groups are then matched $1: 1$ for the same propensity score value to neutralize imbalances between groups [102,125,126]. The analysis may use propensity scores in a variety of way, for example for stratifying and matching treated and untreated patients [124,125,127-129]. Identifying the true confounding parameters that should be included in the model represents a challenge and is the object of debate [101]. Some relevant recommendations suggest that the propensity scores should be based on all variables potentially related to the outcome $[129,130]$, or any variables linked with treatment choice and results [123]. This method helps to balance the occurrence of confounders between treated and untreated groups [101]. Propensity scores for studies on asthma should be based on all the determinants of asthma control and severity, the frequency of exacerbations and short acting beta2agonist use [14,131].

Regarding COPD, the most recent study to use propensity score matching to counterbalance the absence of randomization and potential confounding factors was the PATHOS trial. This Swedish retrospective, observational study compared exacerbation rates (defined as hospitalizations, emergency visits and administration of

Table 3

Strategies for overcoming the limitations of real life studies.

\begin{tabular}{|c|c|c|}
\hline Problem or limitation & Solution purposes & Complementarities by RCTs \\
\hline $\begin{array}{l}\text { - Lack of patient selection brings confounding factors } \\
\text { - Lack of randomization }\end{array}$ & A priori strict critical design. & $\begin{array}{l}\text { - Rigorous experimental design } \\
\text { - Randomization } \\
\text { - Blinding }\end{array}$ \\
\hline $\begin{array}{l}\text { - Absence of blinding } \\
\text { - Residual monitoring bias }\end{array}$ & $\begin{array}{l}\text { Report the results in a correct, accurate and reliable way } \\
\text { following appropriate statements. }\end{array}$ & - Rigorous analytical method \\
\hline - Immortality bias & Time-dependent analysis. & $\begin{array}{l}\text { - Rigorous experimental design } \\
\text { - Rigorous analytical method }\end{array}$ \\
\hline - Confounding by indication & Propensity score. & $\begin{array}{l}\text { - Randomization } \\
\text { - Blinding }\end{array}$ \\
\hline
\end{tabular}

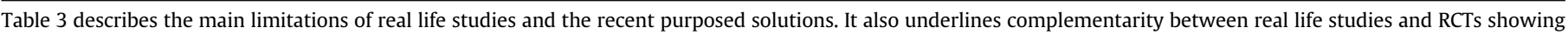
how some of these solutions derives from the analysis of RCTs strengths/advantages. 
oral steroids or antibiotics for COPD) in patients with moderate to severe COPD who had been treated with either budesonide/formoterol or fluticasone/salmeterol [132]. Information was collected for more than 21,000 patients followed for up to 11 years from primary care medical records and data from national hospital, pharmacy and cause of death registries [132]. A propensity score was calculated based on age, gender, lung function, number of outpatient visits for acute exacerbations, number of prescriptions for other medications, significant comorbidities, and number of previous hospitalizations [132]. A score between 0 and 1 was given to each patient and a very tight matching was performed. Two matched cohorts of 2734 patients each were identified, with a follow-up comprising more than 19,000 patient-years. The study reports that treatment with budesonide/formoterol significantly reduces the number of exacerbations and hospitalizations compared to fluticasone/salmeterol [132].

\section{Conclusions}

RCTs are essential research tools with strong internal validity but low generalizability to real life conditions [7,14]. Thus, there is an increased interest in real life studies because of their close association with routine clinical practice [7]. Unfortunately, the main limitation of these latter studies is the lack of internal validity.

RCTs and real life studies have opposite strengths, in terms of validity. This has both negative and positive implications. On the negative side, results obtained from only one type of study should be interpreted cautiously [82]. On a positive note, these approaches are complementary, so combining them increases their relative value and helps overcoming their relative limitations. Comparing effectiveness and efficacy trials can provide important information, even if they produce discordant results. This may indicate that the intervention is appropriate under some conditions, but not others [105]. On this basis, it is plausible to propose a workflow in which results from RCTs need to be confirmed by real life studies. As an example, the results from a RCT in which a therapeutic option in asthma is superior to the conventional treatment is then validated in a larger real life setting.

It is important to recognize the characteristics of each type of study and accentuate their strengths while attempting to address their limitations through remedial strategies [30]. Propensity score best represents this concept, increasing the reliability of the conclusions of observational studies where randomization cannot be applied. Clinical research evolves also in the search of solutions to its own limitations.

\section{Disclosure of conflicts of interest}

We wish to confirm that there are no known conflicts of interest associated with this publication.

We also confirm that the manuscript has been read and approved by all named authors.

\section{References}

[1] Riegelman R. Studying a study and testing a test: how to read the medical evidence. Philadelphia, PA: Lippincott Williams \& Wilkins; 2000.

[2] Nallamothu B, Hayward RA, Bates ER. Beyond the randomized clinical trial: the role of effectiveness studies in evaluating cardiovascular therapies. Circulation 2008;118(12):1294-303. http://dx.doi.org/10.1161/ CIRCULATIONAHA.107.703579.

[3] Roland M, Torgerson DJ. What are pragmatic trials? BMJ 1998;316:285. http://dx.doi.org/10.1136/bmj.316.7127.285.

[4] Compher C. Efficacy vs effectiveness. JPEN J Parenter Enteral Nutr 2010;34(6): 598-9. http://dx.doi.org/10.1177/0148607110381906.

[5] Stanley K. Design of randomized controlled trials. Circulation 2007;115: 1164-9. http://dx.doi.org/10.1161/CIRCULATIONAHA.105.594945.
[6] Stanley K. Evaluation of randomized controlled trials. Circulation 2007;115: 1819-22. http://dx.doi.org/10.1161/CIRCULATIONAHA.106.618603.

[7] Price D, Chisholm A, van der Molen T, Roche N, Hillyer EV, Bousquet J. Reassessing the evidence hierarchy in asthma: evaluating comparative effectiveness. Curr Allergy Asthma Rep 2011;11(6):526-38. http://dx.doi. org/10.1007/s11882-011-0222-7.

[8] Price D, Roche N, Martin R, Chisholm A, Respiratory Effectiveness Group Collaborators. Feasibility and ethics. Am J Respir Crit Care Med 2013;188: 1368-9. http://dx.doi.org/10.1164/rccm.201307-1250LE.

[9] Roche N, Reddel HK, Agustì A, Bateman ED, Krishnan JA, Martin RJ, et al. Integrating real-life studies in the global therapeutic research framework. Lancet Respir Med 2013;1:e29-30. http://dx.doi.org/10.1016/S22132600(13)70199-1.

[10] Concato J. Study design and "evidence" in patient-oriented research. Am J Respir Crit Care Med 2013;187:1167-72. http://dx.doi.org/10.1164/rccm. 201303-05210E.

[11] Albert R. "Lies, damned lies..." and observational studies in comparative effectiveness research. Am J Respir Crit Care Med 2013;187:1173-7. http:// dx.doi.org/10.1164/rccm.201212-21870E.

[12] Nichol A, Bailey M, Cooper DJ, POLAR; EPO Investigators. Challenging issues in randomised controlled trials. Injury 2010;41(Suppl. 1):S20-3. http://dx. doi.org/10.1016/j.injury.2010.03.033.

[13] Jaillon P. Controlled randomized clinical trials [Article in French] Bull Acad Natl Med 2007;191(4-5):739-56.

[14] Price D, Hillyer EV, van der Molen T. Efficacy versus effectiveness trials: informing guidelines for asthma management. Curr Opin Allergy Clin Immunol 2013;13(1):50-7. http://dx.doi.org/10.1097/ACl.0b013e32835ad059.

[15] US Preventive Services Task Force. Guide to clinical preventive services: report of the US Preventive Services Task Force. 2nd ed. Baltimore, MD: Williams \& Wilkins; 1996.

[16] Samet J. Measuring the effectiveness of inhaled corticosteroids for COPD is not easy! Am J Respir Crit Care Med 2003;168(1):1-2. http://dx.doi.org/10. $1164 / \mathrm{rccm} .2304004$.

[17] British guideline on the management of asthma. A national clinical guideline.http://www.sign.ac.uk/guidelines/fulltext/101/index.html; May 2008. Revised June 2009.

[18] Reddel H, Taylor DR, Bateman ED, Boulet LP, Boushey HA, Busse WW, et al. An official American Thoracic Society/European Respiratory Society statement: asthma control and exacerbations: standardizing endpoints for clinical asthma trials and clinical practice. Am J Respir Crit Care Med 2009;180: 59-99. http://dx.doi.org/10.1164/rccm.200801-060ST.

[19] GINA report. Global strategy for asthma management and prevention. Updated December 2012. http://www.ginasthma.org.

[20] Vercken J. Randomized therapeutic trials of community-acquired lung diseases. Analysis of studies published between 1978 and 1988. Rev Pneumol Clin 1991;47(1):21-7.

[21] Altenburg J, de Graaff CS, Stienstra Y, Sloos JH, van Haren EH, Koppers RJ, et al. Effect of azithromycin maintenance treatment on infectious exacerbations among patients with non-cystic fibrosis bronchiectasis: the BAT randomized controlled trial. J Am Med Assoc 2013;309(12):1251-9. http:// dx.doi.org/10.1001/jama.2013.1937.

[22] McKee M, Britton A, Black N, McPherson K, Sanderson C, Bain C. Methods in health services research: interpreting the evidence: choosing between randomised and non-randomised studies. BMJ 1999;319:312-5. http://dx. doi.org/10.1136/bmj.319.7205.312.

[23] Estellat C, Torgerson DJ, Ravaud P. How to perform a critical analysis of a randomised controlled trial. Best Pract Res Clin Rheumatol 2009;23(2):291303. http://dx.doi.org/10.1016/j.berh.2009.03.003.

[24] Wood L, Egger M, Gluud LL, Schulz KF, Jüni P, Altman DG, et al. Empirical evidence of bias in treatment effect estimates in controlled trials with different interventions and outcomes: meta-epidemiological study. BMJ 2008;336(7644):601-5. http://dx.doi.org/10.1136/bmj.39465.451748.AD.

[25] Hollis S, Campbell F. What is meant by intention to treat analysis? Survey of published randomised controlled trials. BMJ 1999;319:670-4. http://dx.doi. org/10.1136/bmj.319.7211.670.

[26] Rothwell P. External validity of randomised controlled trials: "to whom do the results of this trial apply?". Lancet 2005;365(9453):82-93. http://dx.doi. org/10.1016/S0140-6736(04)17670-8.

[27] Annemans L, Aristides M, Kubin M. Real-life data: a growing need. ISPOR; www.ispor.org/news/articles/oct07/rld.asp.

[28] Järvinen T, Sievänen H, Kannus P, Jokihaara J, Khan KM. The true cost of pharmacological disease prevention. BMJ 2011;342:d2175. http://dx.doi.org/ 10.1136/bmj.d2175.

[29] Krishnan J, Schatz M, Apter AJ. A call for action: comparative effectiveness research in asthma. J Allergy Clin Immunol 2011;127:123-7. http://dx.doi. org/10.1016/j.jaci.2010.08.032.

[30] Ware J, Hamel MB. Pragmatic trials - guides to better patient care? N Engl J Med 2011;364:1685-7. http://dx.doi.org/10.1056/NEJMp1103502.

[31] Herland K, Akselsen JP, Skjønsberg OH, Bjermer L. How representative are clinical study patients with asthma or COPD for a larger "real life" population of patients with obstructive lung disease? Respir Med 2005;99(1):11-9. http://dx.doi.org/10.1016/j.rmed.2004.03.026.

[32] Scichilone N, Basile M, Battaglia S, Bellia V. What proportion of Chronic Obstructive Pulmonary Disease outpatients is eligible for inclusion in randomized clinical trials? Respiration; 2013 Nov 20 [Epub ahead of print]. 
[33] Haughney J, Price D, Kaplan A, Chrystyn H, Horne R, May N, et al. Achieving asthma control in practice: understanding the reasons for poor control. Respir Med 2008;102(12):1681-93. http://dx.doi.org/10.1016/j.rmed.2008. 08.003.

[34] Corrigan C. Asthma therapy: there are guidelines, and then there is real life. Prim Care Respir J 2011:20:13-4. http://dx doi org/10.4104/pcrj.2011.00016.

[35] Lötvall J, Akdis CA, Bacharier LB, Bjermer L, Casale TB, Custovic A, et al. Asthma endotypes: a new approach to classification of disease entities within the asthma syndrome. J Allergy Clin Immunol 2011;127(2):355-60. http://dx.doi.org/10.1016/j.jaci.2010.11.037.

[36] Rand C, Wright RJ, Cabana MD, Foggs MB, Halterman JS, Olson L, et al. Mediators of asthma outcomes. J Allergy Clin Immunol 2012;129(Suppl. 3): S136-41. http://dx.doi.org/10.1016/j.jaci.2011.12.987.

[37] Smith J, Noble MJ, Musgrave S, Murdoch J, Price GM, Barton GR, et al. The at-risk registers in severe asthma (ARRISA) study: a cluster-randomised controlled trial examining effectiveness and costs in primary care. Tho$\operatorname{rax} \quad 2012 ; 67(12): 1052-60$. http://dx.doi.org/10.1136/thoraxjnl-2012202093.

[38] Chaudhuri R, Livingston E, McMahon AD, Thomson L, Borland W Thomson NC. Cigarette smoking impairs the therapeutic response to oral corticosteroids in chronic asthma. Am J Respir Crit Care Med 2003;168(11): 1308-11. http://dx.doi.org/10.1164/rccm.200304-5030C.

[39] Tomlinson J, McMahon AD, Chaudhuri R, Thompson JM, Wood SF Thomson NC. Efficacy of low and high dose inhaled corticosteroid in smokers versus non-smokers with mild asthma. Thorax 2005;60(4):282-7. http://dx. doi.org/10.1136/thx.2004.033688.

[40] Lange P, Parner J, Vestbo J, Schnohr P, Jensen G. A 15-year follow-up study of ventilatory function in adults with asthma. N Engl J Med 1998;339(17): 1194-200. http://dx.doi.org/10.1056/NEJM199810223391703.

[41] Chaudhuri R, Livingston E, McMahon AD, Lafferty J, Fraser I, Spears M, et al Effects of smoking cessation on lung function and airway inflammation in smokers with asthma. Am J Respir Crit Care Med 2006;174(2):127-33. http://dx.doi.org/10.1164/rccm.200510-15890C.

[42] Eisner M, Iribarren C. The influence of cigarette smoking on adult asthma outcomes. Nicotine Tob Res 2007;9:53-6. http://dx.doi.org/10.1080/ 14622200601078293.

[43] Boulet L, FitzGerald JM, McIvor RA, Zimmerman S, Chapman KR. Influence of current or former smoking on asthma management and control. Can Respir J 2008;15(5):275-9.

[44] Krishnan J, Davis SQ, Charbeneau JT, Holguin F, Naureckas ET. Hospitalizations for asthma in the elderly in the U.S. in 2000 and 2005. American Thoracic Society international conference 2008 Am J Respir Crit Care Med 2008 Apr;177. Abstract A667.

[45] National Institutes of Health, National Heart Lung and Blood Institute. Morbidity \& mortality: 2009 chart book on cardiovascular, lung, and blood diseases. http://www.nhlbi.nih.gov/resources/docs/2009_ChartBook.pdf.

[46] Moore W, Meyers DA, Wenzel SE, Teague WG, Li H, Li X, et al. Identification of asthma phenotypes using cluster analysis in the Severe Asthma Research Program. Am J Respir Crit Care Med 2010;181:315-23. http://dx.doi.org/10. 1164/rccm.200906-08960C.

[47] Ozyilmaz E, Kokturk N, Teksut G, Tatlicioglu T. Unsuspected risk factors of frequent exacerbations requiring hospital admission in chronic obstructive pulmonary disease. Int J Clin Pract 2013;67:691-7. http://dx.doi.org/10. 1111/ijcp.12150.

[48] Fabbri LM, Boyd C, Boschetto P, Rabe KF, Buist AS, Yawn B, et al., ATS/ERS Ad Hoc Committee on Integrating and Coordinating Efforts in COPD Guideline Development. How to integrate multiple comorbidities in guideline development: article 10 in integrating and coordinating efforts in COPD guideline development. An official ATS/ERS workshop report. Proc Am Thorac Soc 2012;9:274-81. http://dx.doi.org/10.1513/pats.201208-063ST.

[49] Peters-Golden M, Swern A, Bird SS, Hustad CM, Grant E, Edelman JM. Influence of body mass index on the response to asthma controller agents. Eur Respir J 2006;27:495-503.

[50] Boulet LP, Boulay MÈ. Asthma-related comorbidities. Expert Rev Respir Med 2011;5:377-93. http://dx.doi.org/10.1586/ers.11.34.

[51] Hawkins NM, Wang D, Petrie MC, Pfeffer MA, Swedberg K, Granger CB, et al. Baseline characteristics and outcomes of patients with heart failure receiving bronchodilators in the CHARM programme. Eur J Heart Fail 2010;12:557-65. http://dx.doi.org/10.1093/eurihf/hfq040.

[52] Brooks TW, Creekmore FM, Young DC, Asche CV, Oberg B, Samuelson WM. Rates of hospitalizations and emergency department visits in patients with asthma and chronic obstructive pulmonary disease taking beta-blockers. Pharmacotherapy 2007;27:684-90.

[53] Kunz R, Oxman AD. The unpredictability paradox: review of empirical comparisons of randomised and nonrandomised clinical trials. BM] 1998:317:1185-90. http://dx.doi.org/10.1136/bmj.317.7167.1185.

[54] Giraud V, Roche N. Misuse of corticosteroid metered-dose inhaler is associated with decreased asthma stability. Eur Respir J 2002;19(2):246-51. http://dx.doi.org/10.1183/09031936.02.00218402.

[55] Davies G, Pyke S, Kinmouth AL. Effect of nonattenders on the potential of a primary care programme to reduce cardiovascular risk in the population. BMJ 1994;309:1553-6. http://dx.doi.org/10.1136/bmj.309.6968.1553.

[56] Hunninghake D, Darby CA, Probstfield JL. Recruitment experience in clinical trials: literature summary and annotated bibliography. Control Clin Trials 1987;8:6S-30S. http://dx.doi.org/10.1016/0197-2456(87)90004-3.
[57] Horwitz R. Complexity and contradiction in clinical trial research. Am J Med 1987:82:498-510. http://dx.doi.org/10.1016/0002-9343(87)90450-5.

[58] Colditz G, Brewer TF, Berkey CS, Wilson ME, Burdick E, Fineberg HV, et al Efficacy of BCG vaccine in the prevention of tuberculosis: meta-analysis of the published literature. J Am Med Assoc 1994;271:698-702. http://dx.doi. org/10.1001/jama.1994.03510330076038.

[59] Clemens J, Chuong JJ, Feinstein AR. The BCG controversy. A methodological and statistical reappraisal. J Am Med Assoc 1983;249:2362-9. http://dx.doi. org/10.1001/jama.1983.03330410048027.

[60] Wechsler M, Kelley JM, Boyd IO, Dutile S, Marigowda G, Kirsch I, et al Active albuterol or placebo, sham acupuncture, or no intervention in asthma. N Engl J Med 2011;365(2):119-26. http://dx.doi.org/10.1056/ NEJMoa1103319.

[61] Ryan D, Price D, Musgrave SD, Malhotra S, Lee AJ, Ayansina D, et al. Clinica and cost effectiveness of mobile phone supported self monitoring of asthma: multicentre randomised controlled trial. BMJ 2012;344:e1756. http:// dx.doi.org/10.1136/bmj.e1756.

[62] Konstantinou G. Pragmatic trials: how to adjust for the 'Hawthorne effect'? Thorax 2012;67:562. http://dx.doi.org/10.1136/thoraxjnl-2011-200657.

[63] Baiardini I, Braido F, Bonini M, Compalati E, Canonica GW. Why do doctors and patients not follow guidelines? Curr Opin Allergy Clin Immunol 2009;9: 228-33. http://dx.doi.org/10.1097/ACI.0b013e32832b4651.

[64] Pauwels R, Löfdahl CG, Postma DS, Tattersfield AE, O’Byrne P, Barnes PJ, et al Effect of inhaled formoterol and budesonide on exacerbations of asthma. Formoterol and Corticosteroids Establishing Therapy (FACET) International Study Group. N Engl J Med 1997;337(20):1405-11. http://dx.doi.org/10. 1056/NEJM199711133372001.

[65] Bjermer L, Bisgaard H, Bousquet J, Fabbri LM, Greening AP, Haahtela T, et al Montelukast and fluticasone compared with salmeterol and fluticasone in protecting against asthma exacerbation in adults: one year, double blind, randomised, comparative trial. BMJ 2003;327(7420):891. http://dx.doi.org/ 10.1136/bmj.327.7420.891.

[66] Bateman E, Boushey HA, Bousquet J, Busse WW, Clark TJ, Pauwels RA, et al Can guideline-defined asthma control be achieved? the gaining optimal asthma control study. Am J Respir Crit Care Med 2004;170(8):836-44. http://dx.doi.org/10.1164/rccm.200401-0330C.

[67] Feudtner C, Schreiner M, Lantos JD. Risks (and benefits) in comparative effectiveness research trials. N Engl J Med 2013;369(10):892-4. http://dx. doi.org/10.1056/NEJMp1309322.

[68] Barnes N, Menzies-Gow A, Mansur AH, Spencer D, Percival F, Radwan A, et al. Effectiveness of omalizumab in severe allergic asthma: a retrospective UK real-world study. J Asthma 2013;50(5):529-36. http://dx.doi.org/10.3109/ 02770903.2013.790419.

[69] Folli C, Chiappori A, Pellegrini M, Garelli V, Riccio AM, De Ferrari L, et al. COPD treatment: real life and experimental effects on peripheral NK cells, their receptors expression and their IFN- $\gamma$ secretion. Pulm Pharmacol Ther 2012;25(5):371-6. http://dx.doi.org/10.1016/j.pupt.2012.06.009.

[70] Öztürk C, Kaya A, Bilgin C, Yücesoy L, İkidağ B, Demirel M, et al. Evaluation of inhaler technique and patient satisfaction with fixed-combination budesonide/formoterol dry-powder inhaler in chronic obstructive pulmonary disease (COPD): data on real-life clinical practice in Turkey. Tuberk Torak 2012;60(4):301-13. http://dx.doi.org/10.5578/tt.4634.

[71] Bourbeau J, Saad N, Joubert A, Ouellet I, Drouin I, Lombardo C, et al. Making collaborative self-management successful in COPD patients with high disease burden. Respir Med 2013;107(7):1061-5. http://dx.doi.org/10.1016/j. rmed.2013.03.003.

[72] Braido F, Brusselle G, Ingrassia E, Nicolini G, Price D, Roche N, et al. International cross-sectional and longitudinal assessment on asthma control in European adult patients - the LIAISON study protocol. BMC Pulm Med 2013;13:18. http://dx.doi.org/10.1186/1471-2466-13-18.

[73] Price D, Asukai Y, Ananthapavan J, Malcolm B, Radwan A, Keyzor I. A UKbased cost-utility analysis of indacaterol, a once-daily maintenance bronchodilator for patients with COPD, using real world evidence on resource use. Appl Health Econ Health Policy 2013;11(3):259-74. http://dx.doi.org/ 10.1007/s40258-013-0021-5.

[74] Scichilone N, Spatafora M, Battaglia S, Arrigo R, Benfante A, Bellia V. Lung penetration and patient adherence considerations in the management of asthma: role of extra-fine formulations. J Asthma Allergy 2013;6:11-21. http://dx doi.org/10.2147/JAA.S14743.

[75] van Nooten F, Stern S, Braunstahl GJ, Thompson C, Groot M, Brown RE. Costeffectiveness of omalizumab for uncontrolled allergic asthma in the Netherlands. J Med Econ 2013;16(3):342-8. http://dx.doi.org/10.3111/ 13696998.2012.756398.

[76] Tunis S, Stryer DB, Clancy CM. Practical clinical trials: increasing the value of clinical research for decision making in clinical and health policy. J Am Med Assoc 2003;290:1624-32. http://dx.doi.org/10.1001/jama.290.12.1624.

[77] Zwarenstein M, Treweek S, Gagnier JJ, Altman DG, Tunis S, Haynes B, et al Improving the reporting of pragmatic trials: an extension of the CONSORT statement. BMJ 2008;337:a2390. http://dx.doi.org/10.1136/bmj.a2390.

[78] Chalkidou K, Tunis S, Whicher D, Fowler R, Zwarenstein M. The role for pragmatic randomized controlled trials (pRCTs) in comparative effectiveness research. Clin Trials 2012;9:436-46. http://dx.doi.org/10.1177/1740774512450097.

[79] Sarrazin M, Rosenthal GE. Finding pure and simple truths with administrative data. J Am Med Assoc 2012;307:1433-5. http://dx.doi.org/10.1001/ jama.2012.404. 
[80] Di Marco F, Tantucci C, Pellegrino G, Centanni S. Chronic obstructive pulmonary disease diagnosis: the simpler the better? Not always. Eur J Intern Med 2013;24:199-202. http://dx.doi.org/10.1016/j.ejim.2013.01.008.

[81] Bombardier C, Maetzel A. Pharmacoeconomic evaluation of new treatments: efficacy versus effectiveness studies? Ann Rheum Dis 1999;58(Suppl. 1): I82-5. http://dx.doi.org/10.1136/ard.58.2008.i82.

[82] Concato J, Shah N, Horwitz RI. Randomized, controlled trials, observational studies, and the hierarchy of research designs. N Engl J Med 2000;342:188792. http://dx.doi.org/10.1056/NEJM200006223422507.

[83] Rabe K, Adachi M, Lai CK, Soriano JB, Vermeire PA, Weiss KB, et al. Worldwide severity and control of asthma in children and adults: the global asthma insights and reality surveys. Allergy Clin Immunol 2004;114(1):407. http://dx.doi.org/10.1016/j.jaci.2004.04.042.

[84] Melani A, Bonavia M, Cilenti V, Cinti C, Lodi M, Martucci P, et al. Inhaler mishandling remains common in real life and is associated with reduced disease control. Respir Med 2011;105(6):930-8. http://dx.doi.org/10.1016/j. rmed.2011.01.005.

[85] Brocklebank D, Ram F, Wright J, Barry P, Cates C, Davies L, et al. Comparison of the effectiveness of inhaler devices in asthma and chronic obstructive airways disease: a systematic review of the literature. Health Technol Assess 2001;5(26):1-149.

[86] Dolovich M, Ahrens RC, Hess DR, Anderson P, Dhand R, Rau JL, et al. Device selection and outcomes of aerosol therapy: evidence-based guidelines: American College of Chest Physicians/American College of Asthma, Allergy and Immunology. Chest 2005;127(1):335-71. http://dx.doi.org/10.1378 chest.127.1.335.

[87] National Asthma Education And Prevention Program. Expert panel report 3: guidelines for the diagnosis and management of asthma. Full report, http:// www.nhlbi.nih.gov/guidelines/asthma/asthgdln.pdf; 2007.

[88] Papi A, Haughney J, Virchow JC, Roche N, Palkonen S, Price D. Inhaler devices for asthma: a call for action in a neglected field. Eur Respir J 2011;37(5):9825. http://dx.doi.org/10.1183/09031936.00150910.

[89] Price D, Chrystyn H, Kaplan A, Haughney J, Román-Rodríguez M, Burden A, et al. Effectiveness of same versus mixed asthma inhaler devices: a retrospective observational study in primary care. Allergy Asthma Immunol Res 2012;4(4):184-91. http://dx.doi.org/10.4168/aair.2012.4.4.184.

[90] Price D, Haughney J, Sims E, Ali M, von Ziegenweidt J, Hillyer EV, et al Effectiveness of inhaler types for real-world asthma management: retrospective observational study using the GPRD. J Asthma Allergy 2011;4:3747. http://dx.doi.org/10.2147/JAA.S17709.

[91] Price D, Roche N, Christian Virchow J, Burden A, Ali M, Chisholm A, et al. Device type and real-world effectiveness of asthma combination therapy: an observational study. Respir Med 2011;105(10):1457-66. http://dx.doi.org 10.1016/j.rmed.2011.04.010.

[92] Müller V, Gálffy G, Eszes N, Losonczy G, Bizzi A, Nicolini G, et al. Asthma control in patients receiving inhaled corticosteroid and long-acting beta2agonist fixed combinations. A real-life study comparing dry powder inhalers and a pressurized metered dose inhaler extrafine formulation. BMC Pulm Med 2011;11:40. http://dx.doi.org/10.1186/1471-2466-11-40.

[93] Santus P, Picciolo S, Proietto A, Falcone F, Mangiacavallo A, Pellegrino G, et al Doctor-patient relationship: a resource to improve respiratory diseases management. Eur J Intern Med 2012;23:442-6. http://dx.doi.org/10.1016/j. ejim.2012.04.004.

[94] Price D, Robertson A, Bullen K, Rand C, Horne R, Staudinger H. Improved adherence with once-daily versus twice-daily dosing of mometasone furoate administered via a dry powder inhaler: a randomized open-label study. BMC Pulm Med 2010;10:1. http://dx.doi.org/10.1186/1471-2466-10-1.

[95] Price D, Musgrave SD, Shepstone L, Hillyer EV, Sims EJ, Gilbert RF, et al. Leukotriene antagonists as first-line or add-on asthma-controller therapy. $\mathrm{N} \mathrm{Engl}$ Med 2011;364(18):1695-707. http://dx.doi.org/10.1056/NEJMoa1010846.

[96] Ducharme F, Noya FJ, Allen-Ramey FC, Maiese EM, Gingras J, Blais L. Clinical effectiveness of inhaled corticosteroids versus montelukast in children with asthma: prescription patterns and patient adherence as key factors. Curr Med Res Opin 2012;28(1):111-9. http://dx.doi.org/10.1185/03007995.2011.640668.

[97] van Staa T, Leufkens HG, Zhang B, Smeeth L. A comparison of cost effectiveness using data from randomized trials or actual clinical practice: selective cox-2 inhibitors as an example. PLoS Med 2009;6:e1000194. http:// dx.doi.org/10.1371/journal.pmed.1000194.

[98] Rizzo J, Powe NR. Methodological hurdles in conducting pharmacoeconomic studies. Pharmacoeconomics 1999;15:339-55. http://dx.doi.org/10.2165/ 00019053-199915040-00002.

[99] Stempel D, Roberts CS, Stanford RH. Treatment patterns in the months prior to and after asthma-related emergency department visit. Chest 2004;126(1): 75-80. http://dx.doi.org/10.1378/chest.126.1.75.

[100] Molimard M, Raherison C, Lignot S, Depont F, Abouelfath A, Moore N. Assessment of handling of inhaler devices in real life: an observational study in 3811 patients in primary care. Aerosol Med 2003;16(3):249-54. http://dx. doi.org/10.1089/089426803769017613.

[101] Austin P, Grootendorst P, Anderson GM. A comparison of the ability of different propensity score models to balance measured variables between treated and untreated subjects: a Monte Carlo study. Stat Med 2007;26(4): 734-53. http://dx.doi.org/10.1002/sim.2580.

[102] Thomas M, Cleland J, Price D. Database studies in asthma pharmacoeconomics: uses, limitations and quality markers. Expert Opin Pharmacother 2003;4:351-8. http://dx.doi.org/10.1517/14656566.4.3.351.
[103] Ernst E, Canter PH. Limitations of "pragmatic" trials. Postgrad Med J 2005;81: 203. http://dx.doi.org/10.1136/pgmj.2004.026807.

[104] Resch KL. Pragmatic trials: propaganda or research tool? Focus Altern Complement Ther 2005;10:181-3. http://dx.doi.org/10.1211/fact.10.3.0006.

[105] Kent D, Kitsios G. Against pragmatism: on efficacy, effectiveness and the real world. Trials 2009;10:48. http://dx.doi.org/10.1186/1745-6215-10-48.

[106] Haut E, Pronovost PJ. Surveillance bias in outcomes reporting. J Am Med Assoc 2011;305(23):2462-3. http://dx.doi.org/10.1001/jama.2011.822.

[107] Pierce C, Haut ER, Kardooni S, Chang DC, Efron DT, Haider A, et al. Surveillance bias and deep vein thrombosis in the National Trauma Data Bank: the more we look, the more we find. J Trauma 2008;64(4):932-7. http://dx.doi. org/10.1097/TA.0b013e318166b808.

[108] Salas M, Hofman A, Stricker BH. Confounding by indication: an example of variation in the use of epidemiologic terminology. Am J Epidemiol 1999;149: 981-3. http://dx.doi.org/10.1093/oxfordjournals.aje.a009758.

[109] Hennekens C, Buring JE. Epidemiology in medicine. Boston, MA: Little, Brown \& Co; 1987. pp. 272-86.

[110] Blais L, Ernst P, Suissa A. Confounding by indication and channeling over time: the risks of beta2-agonists. Am J Epidemiol 1996;144:1161-9. http:// dx.doi.org/10.1093/oxfordjournals.aje.a008895.

[111] Kozyrskyj A, Ernst P, Becker AB. Increased risk of childhood asthma from antibiotic use in early life. Chest 2007;131(6):1753-9. http://dx.doi.org/10. 1378/chest.06-3008.

[112] Alm B, Erdes L, Möllborg P, Pettersson R, Norvenius SG, Aberg N, et al. Neonatal antibiotic treatment is a risk factor for early wheezing. Pediatrics 2008;121(4):697-702. http://dx.doi.org/10.1542/peds.2007-1232.

[113] Almqvist C, Wettermark B, Hedlin G, Ye W, Lundholm C. Antibiotics and asthma medication in a large register-based cohort study - confounding, cause and effect. Clin Exp Allergy 2012;42(1):104-11. http://dx.doi.org/10. 1111/j.1365-2222.2011.03850.x.

[114] Heintze K, Petersen KU. The case of drug causation of childhood asthma: antibiotics and paracetamol. Eur J Clin Pharmacol 2013;69(6):1197-209. http://dx.doi.org/10.1007/s00228-012-1463-7.

[115] Cullinan P, Harris J, Mills P, Moffat S, White C, Figg J, et al. Early prescriptions of antibiotics and the risk of allergic disease in adults: a cohort study. Thorax 2004;59(1):11-5

[116] Sin D, Tu JV. Inhaled corticosteroids and the risk of mortality and readmission in elderly patients with chronic obstructive pulmonary disease. Am J Respir Crit Care Med 2001;164(4):580-4. http://dx.doi.org/10.1164/ajrccm. 164.4.2009033.

[117] Suissa S. Effectiveness of inhaled corticosteroids in chronic obstructive pulmonary disease: immortal time bias in observational studies. Am J Respir Crit Care Med 2003;168(1):49-53. http://dx.doi.org/10.1164/rccm.20021012310C.

[118] Horwitz R, Viscoli CM, Clemens JD, Sadock RT. Developing improved observational methods for evaluating therapeutic effectiveness. Am J Med 1990;89:6308. http://dx.doi.org/10.1016/0002-9343(90)90182-D.

[119] von Elm E, Altman DG, Egger M, Pocock SJ, Gøtzsche PC, Vandenbroucke JP, et al. The Strengthening the Reporting of Observational Studies in Epidemiology (STROBE) statement: guidelines for reporting observational studies. Lancet 2007;370(9596):1453-7. http://dx.doi.org/10.1016/S0140-6736(07) 61602-X.

[120] Begg C, Cho M, Eastwood S, Horton R, Moher D, Olkin I, et al. Improving the quality of reporting of randomized controlled trials. The CONSORT statement. J Am Med Assoc 1996;276(8):637-9. http://dx.doi.org/10.1001/jama. 276.8.637.

[121] Campbell M, Elbourne DR, Altman DG. CONSORT statement: extension to cluster randomised trials. BMJ 2004;328:702-8. http://dx.doi.org/10.1136/ bmj.328.7441.702.

[122] Campbell M, Piaggio G, Elbourne DR, Altman DG, CONSORT Group. Consort 2010 statement: extension to cluster randomised trials. BMJ 2012;345: e5661. http://dx.doi.org/10.1136/bmj.e5661.

[123] Perkins S, Tu W, Underhill MG, Zhou XH, Murray MD. The use of propensity scores in pharmacoepidemiologic research. Pharmacoepidemiol Drug Saf 2000;9(2):93-101. http://dx.doi.org/10.1002/(SICI)1099-1557(200003/04)9: 2\%3C93::AID-PDS474\%3E3.0.CO;2-I.

[124] Newgard C, Hedges JR, Arthur M, Mullins RJ. Advanced statistics: the propensity score - a method for estimating treatment effect in observational research. Acad Emerg Med 2004:11(9):953-61.

[125] Rosenbaum P, Rubin DB. The central role of the propensity score in observational studies for causal effects. Biometrika 1983;70:41-55. http://dx.doi. org/10.1093/biomet/70.1.41.

[126] Rosenbaum P, Rubin DB. Reducing bias in observational studies using subclassification on the propensity score. J Am Stat Assoc 1984;79:516-24. http://dx.doi.org/10.1080/01621459.1984.10478078.

[127] D'Agostino R. Tutorial in biostatistics - propensity score methods for bias reduction in the comparison of a treatment to a non-randomized control group. Stat Med 1998;17:2265-81. http://dx.doi.org/10.1002/(SICI)10970258(19981015)17:19\%3C2265::AID-SIM918\%3E3.0.CO;2-B.

[128] Little R, Rubin DB. Causal effects in clinical and epidemiological studies via potential outcomes: concepts and analytical approaches. Annu Rev Public Health 2000;21:121-45. http://dx.doi.org/10.1146/annurev.publhealth.21.1.121.

[129] Rubin D. Estimating causal effects from large data sets using propensity scores. Ann Intern Med 1997;127:757-63. http://dx.doi.org/10.7326/00034819-127-8_Part_2-199710151-00064. 
[130] Heinze G, Jüni P. An overview of the objectives of and the approaches to propensity score analyses. Eur Heart J 2011;32(14):1704-8. http://dx.doi. org/10.1093/eurheartj/ehr031.

[131] Barnes N, Price D, Colice G, Chisholm A, Dorinsky P, Hillyer EV, et al. Asthma control with extrafine-particle hydrofluoroalkane-beclometasone vs. largeparticle chlorofluorocarbon-beclometasone: a real-world observational study. Clin Exp Allergy 2011;41(11):1521-32. http://dx.doi.org/10.1111/j. 1365-2222.2011.03820.x.

[132] Larsson K, Janson C, Lisspers K, Jørgensen L, Stratelis G, Telg G, et al. Combination of budesonide/formoterol more effective than fluticasone/salmeterol in preventing exacerbations in chronic obstructive pulmonary disease. The PATHOS study.J Intern Med 2013;273(6):584-94. http://dx.doi.org/10.1111/joim.12067. 